\title{
Influence of Conative Characteristics on Special Olympics Athletes and Unified Partners' Success in Football
}

\author{
Milos Popovica, Veroljub Stankovic ${ }^{a}$, Dragan Popovic ${ }^{a}$, Evagelia Bolia, Vladimir Savic ${ }^{a}$, Milica Bojovic ${ }^{a}$
}

\begin{abstract}
The research was conducted in order to determine influence of conative characteristics on the criterion variables in Special Olympics athletes and partners in football. For this purpose, 80 athletes and partners engaged in football were tested. For the assessment of conative characteristics, the measurement instrument CON6 was selected by which the following conative regulators were evaluated: activity regulator, organ function regulator, defense reaction regulator, attack reaction regulator, system for coordination of regulatory functions, system for integration of regulatory functions, and system for excitation and inhibition. To assess success in a football game, the following variables were used: evaluation of the effectiveness of the techniques, evaluation of the performance effectiveness in the offensive phase, evaluation of the performance effectiveness in the defensive phase, evaluation of individual creativity during the game, team responsibility evaluation, engagement evaluation, behavior evaluation, general evaluation of success in the game. All the data in this research were analyzed at the Multidisciplinary Research Center, Faculty of Sport and Physical Education, University of Pristina, by the system of data processing programs DRSOFT developed by D. Popović and K. Momirović. The algorithms and programs implemented within this thesis have been fully presented and the results of the programs have been analyzed.
\end{abstract}

Keywords

Reliability, latent, dimension, matrix, vectors, variance

The United Nations experts' estimates indicate that today, there are about 800 million people in the world to whom the term "people with disabilities" can be applied. That amounts almost $10 \%$ of the world population (World Health Organization [WHO], 2000) and represents a major health, social, economic, and political problem that tends to increase.

Based on UNESCO (United Nations Educational, Scientific, and Cultural Organization) provisions (1990, 1995, 1997), great attention is paid to early treatment of children, and according to their new classification, a new system of primary education continues after the preschool treatment, so that professional orientation could start in primary school to continue and grow into vocational rehabilitation in high school. New ideas and suggestions contributing to further solution of all the issues of diagnosis, rehabilitation, and protection of disabled persons are of vital importance for their further treatment.

In 2000, the World Congress in Beijing pointed

\footnotetext{
aUniversity of Pristina, Serbia

\section{Correspondent Author:}

Dragan Popovic, Kosanciceva 17, Krusevac, Serbia, Zip code 37000

E-mail: bogdragan.popovic@gmail.com
} 
out that application of new methods, techniques, and technologies during education, vocational training and employment of disabled persons, facilitates career choice and success at work. Much faster and more modern application of new aids for school, work, and overall life make it easier for handicapped people to achieve success in all fields. Ongoing monitoring and inclusion of the system of disabled people in the mental health movement, which is spreading, aim at preventing growing forms of mental stress and diseases by informing the public about the abilities and opportunities of these people, discovering new ways and forms of assistance. Among disabled people, there are certainly a great number of those with mild mental disabilities. The society is increasingly making efforts to improve the lives of people with such personality profile and their involvement in sports is surely very useful for them.

\section{METHODS}

\section{Sample of Respondents}

To carry out the research correctly and obtain results stable enough in terms of sampling error, it was necessary to take a sufficient number of respondents in the sample. The sample size for this type of research was conditioned by the objectives and tasks of the research, the population size, and degree of variability of the applied system of parameters.

Based on the chosen statistical-mathematical model and program, objectives and hypotheses, the authors opted to include 40 respondents in the sample, a total of 80 in each subsample (40 Special Olympics athletes and 40 partners). The size of such a sample should meet the following criteria:

(1) The effective of the sample should be such as to permit as many degrees of freedom as to make it possible for any coefficient in the pattern matrix or any correlation coefficient equal to or larger than .30 to be considered different from zero with an inference error less than .01;

(2) To use adequate statistical methods successfully, according to the latest beliefs, the number of subjects in the sample should be five times larger than the number of the variables applied.

In addition, respondents were to meet the specific requirements:

(1) Respondents were male;

(2) The age of respondents was defined on the basis of chronological age, so the research covered respondents aged 15 to 18 years plus-minus .5 years;

(3) Respondents were required to be members of a society that brings together Special Olympics athletes;

(4) Respondents were required to attend training classes regularly what was determined on the basis of records kept by the coaches.

In defining the population from which the sample was drawn, except the above, no other restrictions or stratification variables were applied. The measurement was carried out in organizations and schools that bring together children with special needs.

\section{Sample of Conative Variables}

For the assessment of conative characteristics, the measurement instrument CON6 was selected by which the following conative regulators were evaluated:

(1) Activity regulator (EPSILON);

(2) Organ function regulator (CHI);

(3) Defense reaction regulator (ALPHA);

(4) Attack reaction regulator (SIGMA);

(5) System for coordination of regulatory functions (DELTA);

(6) System for integration of regulatory functions (ETA).

\section{Sample of Variables for Evaluation of Success in a Football Game}

For the evaluation of success in a football game, the following elements were measured by this program: 
(1) Football techniques (STEH);

(2) Offensive tactics (SNAP);

(3) Creativity (SSTC);

(4) Defensive tactics (SODB);

(5) Playing behavior (SPON);

(6) Responsibility (SODG);

(7) Engagement (SANG);

(8) General assessment of success in the game (SOUS).

\section{Data Processing Methods}

As regression analysis in the Mahalanobis space has very convenient comparative characteristics relative to the standard canonical model of multivariate regression analysis, an algorithm that generates the largest amount of usable information about the parameters of the model will be described here. The algorithm is implemented by a program written in the matrix language and the performance of the program is shown in some previous studies.

Multivariate regression analysis of criterion variables from $Z_{c}$ in the space of Mahalanobis variables from $\mathrm{M}$ can be defined as a solution to the problem:

$$
\mathrm{M} \beta=\mathrm{Z}_{\mathrm{c}}+\mathrm{E} \mid \operatorname{trag}\left(\mathrm{E}^{\mathrm{t}} \mathrm{E}\right)=\text { minimum. }
$$

As $\mathrm{M}^{\mathrm{t}} \mathrm{M}=\mathrm{I}$, the solution easily obtained by differentiating the function trag $\left(E^{t} E\right)$ is

$$
\beta=M^{t} Z_{c}=R_{r r}^{-1 / 2} R_{r c},
$$

so the matrix of partial regression coefficients is, in fact, a matrix of ordinary product-moment coefficients of correlation between the regressors transformed in a Mahalanobis form and criterion variables. Of course, that is why the asymptotic variance of coefficients $\beta_{\mathrm{jp}}$ from matrix $\beta$ is simply $\sigma_{\mathrm{jp}}{ }^{2}=\left(1-\beta_{\mathrm{jp}}{ }^{2}\right)^{2} \mathrm{n}^{-1}$, and the tests of hypotheses $\mathrm{H}_{0 \mathrm{jp}}$ : $\mathrm{s}_{\mathrm{jp}}{ }^{*}=0$ are easily $\mathrm{f}_{\mathrm{jp}}=\mathrm{s}_{\mathrm{jp}}{ }^{2}\left((\mathrm{n}-2)\left(1-\mathrm{s}_{\mathrm{jp}}{ }^{2}\right)^{-1}\right)$, because under $\mathrm{H}_{0 \mathrm{jp}}: \mathrm{s}_{\mathrm{jp}}{ }^{*}=0$, variables $\mathrm{f}_{\mathrm{jp}}$ have the Fisher-Snedecor F-distribution with 1 and $\mathrm{n}-2$ degrees of freedom.

The regression functions are now defined by the operation $\Psi=\mathrm{M} \beta$ with the covariance matrix $\mathrm{G}=$
$\boldsymbol{\Psi}^{\mathrm{t}} \boldsymbol{\Psi}=\boldsymbol{\beta}^{\mathrm{t}} \boldsymbol{\beta}=\mathrm{R}_{\mathrm{cr}} \mathrm{R}_{\mathrm{rr}}{ }^{-1} \mathrm{R}_{\mathrm{rc}}$,

so the diagonal elements of the matrix $\boldsymbol{\rho}^{2}=\left(\rho_{\mathrm{p}}{ }^{2}\right)=$ diag $\mathrm{G}$ are normal coefficients of determination, and since $Z_{c}{ }_{c}^{t} \Psi=R_{c r} R_{r r}{ }^{-1} R_{r c}=G$, elements $\rho_{p}$ of matrix $\rho$ are ordinary multiple correlation coefficients, and the tests of hypotheses $\mathrm{H}_{0 \mathrm{p}}$ : $\rho_{\mathrm{p}}{ }^{*}=0$ are defined by the functions $f_{p}=\left(\rho_{p}^{2}\left(1-\rho_{p}^{2}\right)^{-1}\right)\left((n-m-1) m^{-1}\right)$, because under $\mathrm{H}_{0 \mathrm{p}}: \rho_{\mathrm{p}}{ }^{*}=0$, functions $\mathrm{f}_{\mathrm{p}}$ have the Fisher-Snedecor F-distribution with $\mathrm{m}$ and $\mathrm{n}-\mathrm{m}-1$ degrees of freedom.

As the matrix of residual variables is $E=Z_{c}-M \beta$, then $W=E^{t} E=R_{c c}-G$ is a matrix of their covariances. Their correlations defined by the matrix $\mathrm{C}=\rho^{-1} \mathrm{G} \rho^{-1}$ are sometimes helpful for identification of regression functions as well as correlations of residual variables defined by the matrix $\boldsymbol{\Phi}=\Sigma^{-1} \mathrm{~W} \Sigma^{-1}$ where $\Sigma^{2}$ $=\operatorname{diag} \mathrm{W}$ is a matrix of variances of residual variables.

The structure of regression factors in the Mahalanobis space is simply $S=M^{t} M \beta \rho^{-1}=\beta \rho^{-1}$, so elements sjp of matrix $\mathrm{S}$ are ordinary product-moment correlation coefficients. Therefore, the asymptotic variance of coefficients sjp from matrix $\mathrm{S}$ is $\xi_{\mathrm{jp}}{ }^{2}=(1-$ $\left.\mathrm{s}_{\mathrm{jp}}{ }^{2}\right)^{2} \mathrm{n}^{-1}$ and the tests of hypotheses $\mathrm{H}_{0 \mathrm{jp}}: \mathrm{s}_{\mathrm{jp}}=0$ are defined by the functions $f_{j p}=s_{j p}{ }^{2}\left((n-2)\left(1-s_{j p}{ }^{2}\right)^{-1}\right)$, because under $\mathrm{H}_{0 \mathrm{jp}}: \mathrm{s}_{\mathrm{jp}}{ }^{*}=0$, variables $\mathrm{f}_{\mathrm{jp}}$ have the Fisher-Snedecor F-distribution with 1 and $n-2$ degrees of freedom.

As $\beta$ is, in fact, a correlation matrix, in the matrix

$$
\mathrm{V}^{2}=\beta \bullet \beta=\left(\mathrm{v}_{\mathrm{jp}}{ }^{2}\right),
$$

where $\bullet$ is an operator of Hadamard multiplication, there will be components of the variances of the regressor and criterion variables under this model of regression analysis. If we now denote the sum vector of row $g$ with $e_{g}$ and the sum vector of row $m$ with $e_{m}$, the elements of the vector:

$$
\mathrm{j}^{2}=\mathrm{V}^{2} \mathrm{e}_{\mathrm{g}}
$$

will be fractions of the variance of each regressor which was involved in the prediction of a set of criterion variables. Of course, in the vector $\left(\mathrm{e}_{\mathrm{m}}{ }^{\mathrm{t}} \mathrm{V}^{2}\right)^{\mathrm{t}}=$ vec $\boldsymbol{\rho}^{2}$ there will be coefficients of determination, and the elements in the columns of matrix $\mathrm{V}^{2}$ are parts of 
Table 1. Regression Analysis of Criteria and Conative Characteristics

\begin{tabular}{lrrrrr}
\hline & $\mathrm{R}$ & Partial R & Beta & $\mathrm{t}$ & Sig. \\
\hline EPSILON & .03 & .03 & .041 & .45 & .65 \\
CH & -.06 & -.06 & -.114 & -.79 & .42 \\
ALPHA & -.05 & -.05 & -.103 & -.69 & .48 \\
SIGMA & .01 & .01 & .013 & .14 & .88 \\
DELTA & .12 & .13 & .176 & 1.61 & .10 \\
ETA & -.13 & -.14 & -.238 & -1.79 & .05 \\
\hline R & $\mathrm{R} \%$ & $\mathrm{df1}$ & $\mathrm{df2}$ & $\mathrm{F}$ & Sig \\
\hline .33 & .11 & 6 & 74 & 3.27 & .00 \\
\hline
\end{tabular}

the variance of each criterion variable that can be attributed to certain regressor variables.

All the data in this research were analyzed at the Multidisciplinary Research Center, Faculty of Sport and Physical Education, University of Pristina by the system of data processing programs DRSOFT developed by D. Popović (1980; 1993a; 1993b) and K. Momirović and D. Popović (2003).

\section{RESULTS}

Modern sports development is increasingly based on scientific research and the cybernetic approach in modeling sports training process. Such an approach requires discovering regularities and relationships between different areas of psychosomatic status responsible for or involved in the execution of various motor tasks in sports.

Modern football has a large complexity and variability of motor actions that are aimed at achieving the highest possible tempo, dynamics, and attractiveness, the optimal personality development of players and finally success in sports competitions.

Football coaches in this country, do not yet use sufficiently scientific research and principles in planning and programming sports training process making it impossible to achieve better athletic performance.
Success in football is possible only if an integral method is used to define the phenomena which are of primary importance for structuring basic movements in a football game, regularities of target transformations, and basic generators of kinesiological activities.

Statistically significant multiple correlation coefficient .33 was obtained by regression analysis of performance effectiveness in a football game as a criterion and predictor system of conative characteristics, indicating that the total valid variance of $11 \%$ with its significance Sig $=.00$ was explained in Table 1. Only one statistically significant direct and partial correlation with the predictor variable was obtained, together with the system for integration of regulatory functions. Based on this sample, it can be said that success in a football game is possible to be explained only by the effectiveness of the system for integration of regulatory functions.

It is reflected in the hypo- or hyperfunction of inhibitory mechanisms in certain situations followed by inhibition of some physiological processes and enhanced egotonicity. This factor of the first row belongs to asthenic (anxiety) syndrome characterized by decreased excitation of the higher centers for regulation and control. It is obvious that it reduces adaptation in sports because it deactivates those structures of the nervous system which are responsible 
for that. This regulator is in a two-way relationship with the defense reaction regulation that modulates tonic arousal.

\section{CONCLUSIONS}

The research was conducted in order to determine influence of conative characteristics on the criterion variables in Special Olympics athletes and partners in football.

For this purpose, 80 athletes and partners engaged in football were tested. For the assessment of conative characteristics, the measurement instrument CON6 was selected by which the following conative regulators were evaluated: activity regulator, organ function regulator, defense reaction regulator, attack reaction regulator, system for coordination of regulatory functions, system for integration of regulatory functions, and system for excitation and inhibition.

To assess success in a football game, the following variables were used: evaluation of the effectiveness of the techniques, evaluation of the performance effectiveness in the offensive phase, evaluation of the performance effectiveness in the defensive phase, evaluation of individual creativity during the game, team responsibility evaluation, engagement evaluation, behavior evaluation, general evaluation of success in the game.

All the data in this research were analyzed at the Multidisciplinary Research Center, Faculty of Sport and Physical Education, University of Pristina, by the system of data processing programs DRSOFT developed by D. Popović (1980; 1993a; 1993b) and K. Momirović and D. Popović (2003).

The algorithms and programs implemented within this thesis have been fully presented and the results of the programs have been analyzed.

Statistically significant multiple correlation coefficient .33 was obtained by regression analysis of performance effectiveness in a football game as a criterion and predictor system of conative characteristics, indicating that the total valid variance of $11 \%$ with its significance $\mathrm{Sig}=.00$ was explained. Only one statistically significant direct and partial correlation with the predictor variable was obtained, together with the system for integration of regulatory functions. Based on this sample, it can be said that success in a football game is possible to be explained only by the effectiveness of the system for integration of regulatory functions.

It is reflected in the hypo- or hyperfunction of inhibitory mechanisms in certain situations followed by inhibition of some physiological processes and enhanced egotonicity. This factor of the first row belongs to asthenic (anxiety) syndrome characterized by decreased excitation of the higher centers for regulation and control. It is obvious that it reduces adaptation in sports because it deactivates those structures of the nervous system which are responsible for that. This regulator is in a two-way relationship with the defense reaction regulation that modulates tonic arousal.

\section{References}

Anderson T. W. 1984. An Introduction to Multivariate Statistical Analysis. 2nd ed. New York: Wiley.

Bartlett, M. S. 1941. "The Statistical Significance of Canonical Correlations." Biometrika 32(1):29-37.

Boli, E. 2011. The Structure of Anthropological Dimensions of Male and Female Dancers and Procedures for Their Evaluation and Monitoring. Monography. Multidisciplinary Research Center, Faculty of Sport and Physical Education, University of Pristina, Leposavic.

Boli, E., D. Popović, A. Hošek-Momirović, J. Popović, and V. Savić. 2012. "Algorithm and Program for Determining Differences in the Level of Personality Characteristics of Male and Female Dancers in Mahalanobis' Space." Kinesmetric 1:17-43.

Boli, E., D. Popovic, and A. Hosek. 2009. Sport and Crime. Multidisciplinary Research Center, Faculty of Sport and Physical Education, University of Pristina, Leposavic.

Boli, E., D. Popovic, and J. Popovic. 2012a. "Differences in the Level of Cognitive Abilities of Male and Female Dancers." International Scientific Journal Kinesmetrics 1:107-119. 
- 2012b. "The Structure of Personality Characteristic of Dancers." Kinesmetric 1:161-177.

Cooley, W. W. and P. R. Lohnes. 1971. Multivariate Data Analysis. New York; London; Sydney; Toronto: John Wiley and Sons, Inc.

Guttman, L. 1945. "A Basis for Analysis of Test-Retest Reliability." Psychometrics 10:255-282.

Momirovic, D., B. Wolf, and D. Popovic. 1999. The Introduction to the Theory of Measurement and Internal Metric Properties of Composite Measuring Instruments. Monography. Faculty of Physical Education, University of Pristina, Pristina.

Momirovic, K. and D. Popovic. 2003. Construction and Application of Taxonomic Neural Networks. Multidisciplinary Research Center, Faculty of Sport and Physical Education, University of Pristina, Leposavic.

Mulaik, S. A. 1972. The Foundations of Factor Analysis. New York: McGraw-Hill.

Popovic, D. 1980. Research Methodology in Physical Education. Scientific Youth, University of Nis, Nis.

—. 1991. Research Methodology in Physical Education (textbook). University of Nis, Scientific Youth, Nis.

- 1992. Methodology of Research in Physical Education. Athens, Greece.

. 1993a. Programs and Subprograms for the Analysis of Quantitative Modifications. Monography. Multidisciplinary Research Center, Faculty of Physical Education, University of Pristina, Pristina.

- 1993b. Determination of the Structure of Psychosomatic Dimensions in Combats and Procedures for Their Evaluation and Monitoring. Monograph. Faculty of Physical Education, University of Pristina, Pristina.

- 2005. "GUTTMAN, Programs for Analysis of Metric Characteristics of Composite Measuring Instruments." In Influence of Situational Training on Transformation of Some Anthropological Dimensions of Selected Football
Players (doctoral thesis), edited by Z. Savić. Faculty of Physical Culture, Leposavic.

Popovic, D., J. Kocic, and E. Boli. 1995. "Conative Characteristics of Female Dancers." Presented at the International Congress "Images of Sport in the World”. P. 96 in 75th Anniversary of the German Sport University. Abstract Volume. Open Forum, Cologne, Germany.

Popovic, D., J. Petrovic, and E. Boli. 1995. "Personality Structure of Female Dancers." Presented at the 3rd International Congress on Physical Education and Sport. Exercise \& Society 11:196. Komotini, Greece.

Popovic, D., V. Stankovic, and Kulic. 1996. "Personality Structure of Handball Players." Presented at the 4th International Congress on Physical Education and Sport. Exercise \& Society 15:164. Komotini, Greece.

\section{Bios}

Milos Popovic, assistant, Faculty of Sport and Physical Education, University of Pristina; research fields: kinesiology and motor control.

Veroljub Stankovic, Ph.D., professor, Faculty of Sport and Physical Education, University of Pristina; research fields: kinesiology and motor control.

Dragan Popovic, Ph.D., professor, Faculty of Sport and Physical Education, University of Pristina; research fields: computational statistics, computer programming, mathematical psychology, kinesiology, and motor control.

Evagelia Boli, Ph.D., professor, Faculty of Sport and Physical Education, University of Pristina; research fields: sociology and dance.

Vladimir Savic, assistant, Faculty of Sport and Physical Education, University of Pristina; research field: methodology.

Milica Bojovic, assistant, Faculty of Sport and Physical Education, University of Pristina; research field: dance. 